\title{
Polymeric amorphous carbon as p-type window within amorphous silicon solar cells
}

\author{
R. U. A. Khan ${ }^{\mathrm{a})}$ \\ Blackett Laboratory, Imperial College London, London SW7 2BW, United Kingdom \\ S. R. P. Silva \\ School of Electronics and Physical Sciences, University of Surrey, Guildford, Surrey GU2 7XH, \\ United Kingdom \\ R. A. C. M. M. van Swaaij \\ Delft University of Technology, DIMES, PO Box 5053, NL-2600, The Netherlands
}

(Received 7 November 2002; accepted 2 April 2003)

\begin{abstract}
Amorphous carbon $(a-\mathrm{C})$ has been shown to be intrinsically $p$-type, and polymeric $a-\mathrm{C}$ (PAC) possesses a wide Tauc band gap of $2.6 \mathrm{eV}$. We have replaced the $p$-type amorphous silicon carbide layer of a standard amorphous silicon solar cell with an intrinsic ultrathin layer of PAC. The thickness of the $p$ layer had to be reduced from 9 to $2.5 \mathrm{~nm}$ in order to ensure sufficient conduction through the PAC film. Although the resulting external parameters suggest a decrease in the device efficiency from $9.2 \%$ to $3.8 \%$ due to a reduced value of open-circuit voltage, the spectral response shows an improvement in the 400-500-nm wavelength range, as a consequence of the wider band gap of the PAC layer. (C) 2003 American Institute of Physics. [DOI: 10.1063/1.1580636]
\end{abstract}

Hydrogenated amorphous silicon $(a-\mathrm{Si}: \mathrm{H})$ is a commonly used thin-film semiconductor for solar cell applications. It possesses a Tauc band gap of $1.7 \mathrm{eV}$, so that the peak in absorption occurs at the optimum energy for coupling to the solar spectrum. However, the performance of the $p-i-n$ structure may be reduced due to the decrease in the band gap of the $p$ layer due to doping, which results in greater optical absorption within this layer and therefore impaired device efficiency, particularly at shorter wavelengths. This is partially overcome with the use of $p$-type amorphous silicon carbide $(a-\mathrm{SiC}: \mathrm{H})$, which possesses a wider Tauc band gap of $1.95 \mathrm{eV}$.

Amorphous carbon $(a-C)$ is a potential candidate for this layer as it has been documented that it is intrinsically $p$-type. ${ }^{1,2}$ Working solar cells comprising $n$ - $\mathrm{C} / p$-Si heterojunctions have been demonstrated. ${ }^{3}$ In particular, polymeric amorphous carbon (PAC) possesses a wide Tauc band gap of $\sim 2.7 \mathrm{eV},{ }^{4}$ which results in reduced absorbance at shorter wavelengths. Furthermore, both the electronic properties and band gap may be optimized ${ }^{5,6}$ by varying the ratio of the $s p^{2}$ and $s p^{3}$ hybridized phases. Transport at room temperature has been attributed to hopping between $s p^{2}$ clusters, ${ }^{7}$ as the gap states are highly localized. ${ }^{8,9}$ However, the low-mobility localized conduction properties of these films are not applicable if an ultrathin $a$-C layer is grown. This would allow the holes to tunnel from the transparent conducting oxide (TCO) contact through to the $i-a-\mathrm{Si}: \mathrm{H}$ layer. It is already possible to improve the blue response of $a$-Si:H solar cells by growing a boron-doped $a-\mathrm{C}$ layer onto an $a$-SiC:H layer. $^{10,11}$ In this letter, we show that if the $a-\mathrm{SiC}: \mathrm{H}$ layer is replaced by an ultrathin $a-\mathrm{C}: \mathrm{H}$ layer an enhanced spectral response at short wavelengths is observed. This demonstrates

a)Electronic mail: riz.khan@ic.ac.uk the possible use of $a-\mathrm{C}: \mathrm{H}$ thin films as a layer in $a-\mathrm{Si}: \mathrm{H}$ solar cells.

The standard $p-i-n a-\mathrm{Si}: \mathrm{H}$ solar cells were deposited using rf-plasma-enhanced chemical vapor deposition (PECVD) onto Asahi U-type TCO. ${ }^{12}$ The layer of PAC was prepared using room temperature rf-PECVD, in a manner described previously. ${ }^{13}$ These films possessed a Tauc band gap of $2.6-2.7 \mathrm{eV}$, a resistivity of $\sim 10^{14} \Omega \mathrm{cm}$, and a refractive index of 1.6. The device structure is shown in Fig. 1. For the back contact, Ag was used in order to obtain optimal reflection. The solar cells were characterized by measuring the external parameters under AM1.5 illumination and the spectral response. From the latter, the quantum efficiency of the cell was extracted.

The external parameters of the $p$-PAC/ $i-a-\mathrm{Si}: \mathrm{H} / n-a-\mathrm{Si}: \mathrm{H}$ solar cell, as compared to a standard $p-a-\mathrm{SiC}: \mathrm{H} / i-a-\mathrm{Si}: \mathrm{H} / n-a-\mathrm{Si}: \mathrm{H}$ device, are shown in Table I. The thickness of both $p$-type layers is also shown for comparison, and it was found that utilizing a thicker layer of PAC $(5 \mathrm{~nm})$ resulted in a vastly reduced photogenerated voltage. This is likely to be due to the high resistivity of the PAC film that would reduce the current to the transparent conducting oxide contact. Also, while the efficiency of the cell has been reduced from $9.2 \%$ to $3.8 \%$, there is little variation in the value of short-circuit current density $\left(J_{\mathrm{sc}}\right)$, which re-

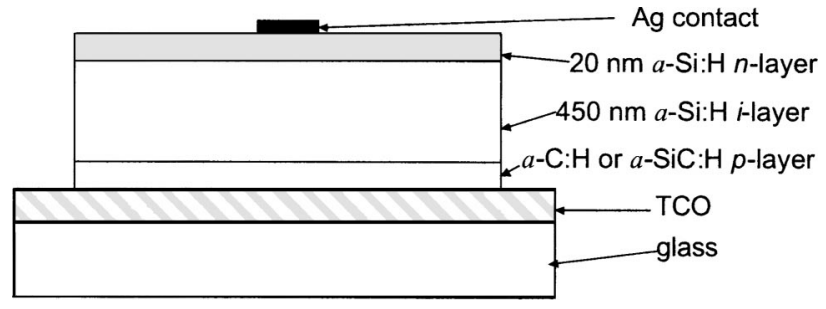

FIG. 1. Device structure for solar cells with $a-\mathrm{SiC}: \mathrm{H}$ or $a-\mathrm{C}: \mathrm{H} p$ layer. 
TABLE I. External parameters for $p-\mathrm{PAC} / i-a-\mathrm{Si}: \mathrm{H} / n-a-\mathrm{Si}: \mathrm{H}$ solar cell, compared to a $p-a-\mathrm{SiC}: \mathrm{H} / i-a-\mathrm{Si}: \mathrm{H} / n-a-\mathrm{Si}: \mathrm{H}$ cell.

\begin{tabular}{lcc}
\hline \hline & $a-\mathrm{C}: \mathrm{H}$ & $a-\mathrm{SiC}: \mathrm{H}$ \\
\hline Thickness $(\mathrm{nm})$ & 2.5 & 9 \\
Efficiency $(\%)$ & 3.84 & 9.20 \\
$J_{\text {sc }}\left(\mathrm{mA} \mathrm{cm}^{-2}\right)$ & 16.3 & 17.2 \\
$V_{\text {oc }}(\mathrm{V})$ & 0.38 & 0.79 \\
Fill factor & 0.62 & 0.68 \\
\hline \hline
\end{tabular}

mains between 16 and $17 \mathrm{~mA} \mathrm{~cm}^{-2}$, and is indicative of the ultrathin PAC film acting as a suitable $p$ layer. The fill factor has also not been significantly reduced by the utilization of the PAC layer, and remains between 0.6 and 0.7. The likely reason for the reduction in cell efficiency is therefore the reduction in open-circuit voltage $V_{\text {oc }}$ from 0.8 to $0.4 \mathrm{~V}$.

To examine reasons for the lower $V_{\text {oc }}$ value, we used previously obtained $I-V$ data for PAC thin films as a function of temperature, where, by fitting to an Arrhenius dependence, an activation energy value of $0.7 \mathrm{eV}$ was derived. This was attributed to the energy difference between the Fermi level and the valence-band density of states. ${ }^{14}$ Using this value, and values of $1.7 \mathrm{eV}$ for the band gap of amorphous silicon and $0.2 \mathrm{eV}$ for the activation energy of $n$-type $a$-Si:H, ${ }^{15}$ we have constructed a band diagram that is shown in Fig. 2. Due to the fact that the conductivity is low within PAC, a significant potential is expected to be dropped over it.

In the theoretical case, for the standard $a$-SiC:H-containing solar cell assuming the parameters shown earlier and a value of activation energy of $0.3 \mathrm{eV}$ for $p$-type $a-\mathrm{Si}: \mathrm{H}$, the internal voltage within the $i$ layer at zero bias is $1.2 \mathrm{~V}$, which equals the voltage required for the flatband condition to occur. Due to the injection of charge from both electrodes, a positive current is measured at this voltage. The $V_{\text {oc }}$ condition is observed at a lower voltage, when the current swept out of the device due to the internal electric field equals the current injected into the device, and has been measured here to be $0.8 \mathrm{~V}$. In the case of the PAC-containing device, the Fermi level is $0.7 \mathrm{eV}$ above the valence-band edge. Therefore, the flat-band condition would be expected to occur at $0.8 \mathrm{~V}$. Assuming that the charge injection is similar in this device, $V_{\text {oc }}$ would be expected to be correspondingly smaller, and is measured here to be $0.4 \mathrm{~V}$. Therefore,

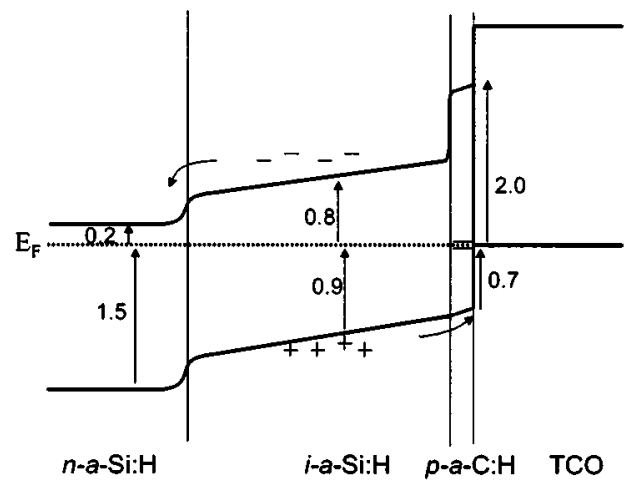

FIG. 2. Band diagram at zero bias showing $n-a-\mathrm{Si}: \mathrm{H} / i-a-\mathrm{Si}: \mathrm{H} / p-a-\mathrm{C}: \mathrm{H}$

structure.
Downloaded 17 Aug 2010 to 131.180.130.114. Redistribution subject to AIP license or copyright; see http://apl.aip.org/about/rights_and_permissions

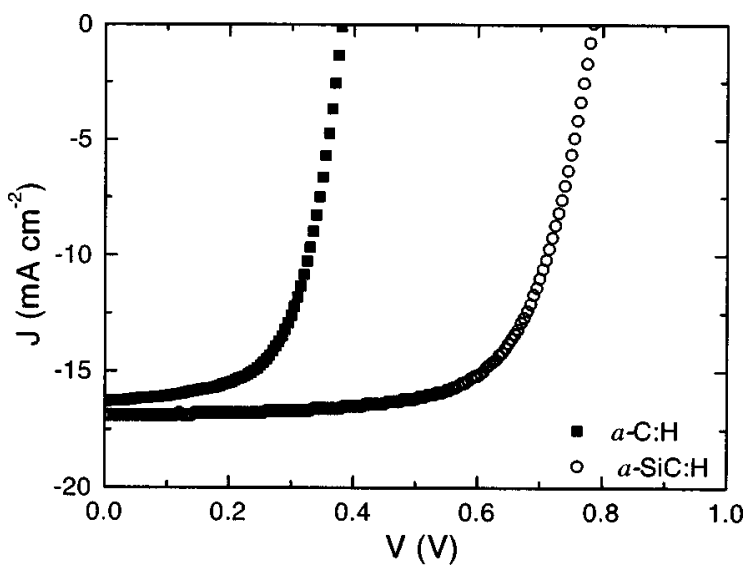

FIG. 3. $I-V$ characteristic for cell containing $a-\mathrm{C}: \mathrm{H} p$ layer as compared to cell containing $a-\mathrm{SiC}: \mathrm{H} p$ layer.

this value is consistent with a greater hole activation energy for PAC as compared to $p$-type $a$-SiC:H.

Figure 3 shows the $I-V$ characteristics for a device containing an $a-\mathrm{C}: \mathrm{H} p$ layer as opposed to one containing an $a-\mathrm{SiC}: \mathrm{H} p$ layer. In this case, it is clearly observed that a smaller value of $V_{\text {oc }}$ will result in a smaller $I-V$ product, and therefore will be expected to reduce the cell efficiency. Therefore, the interpretation outlined earlier suggests the reduction of built-in potential and therefore $V_{\mathrm{oc}}$, and hence the efficiency, of the device.

The variation in quantum efficiency $(\mathrm{QE})$ with incident light wavelength, for different bias voltages, is shown in Fig. 4(a) for the device containing an $a-\mathrm{C}: \mathrm{H} p$ layer and in Fig. 4(b) for one containing an $a-\mathrm{SiC}: \mathrm{H} p$ layer. It may firstly be observed that in the case of Fig. 4(a), however, there is a opposed to a value of $0.6 \mathrm{~V}$ for the $a-\mathrm{SiC}: \mathrm{H}$ containing cell shown in Fig. 4(b). This may be explained by observing Fig. 3 , which shows that at a bias voltage of $0.28 \mathrm{~V}$, the current starts to rise for the $a-\mathrm{C}: \mathrm{H}$ containing cell, resulting in a lower $I-V$ product and hence a reduced QE. In the case of the $a$-SiC:H-containing cell, the current starts to rise above $0.6 \mathrm{~V}$, which would result in a similar decrease in QE. The second and most important point to note, however, is that for devices with an applied voltage of $-0.5 \mathrm{~V}$, the $\mathrm{QE}$ in the $400-500-\mathrm{nm}$ wavelength range increases from 0.62 to 0.82 for the $a-\mathrm{C}: \mathrm{H}$-containing cell, as compared with $0.58-0.82$ for the $a$-SiC:H-containing cell. This demonstrates a small but noticeable increase in the $\mathrm{QE}$ over this wavelength range, and may be attributed to the fact that the $p$-type layer possesses a wider band gap in the case of the $a-\mathrm{C}: \mathrm{H}$-containing cell than for the $a$-SiC:H-containing cell. We have also shown that a tunneling current in the low-mobility $p$-type PAC layer may be used effectively for photovoltaic applications.

In conclusion, the $p$-type $a-\mathrm{SiC}: \mathrm{H}$ layer of a standard amorphous silicon solar cell has been replaced with polymeric amorphous carbon, and a working photovoltaic device has been demonstrated. At a $p$ layer thickness of $2.5 \mathrm{~nm}$, the layer is thin enough for conduction to take place through to the TCO contact, but with larger thicknesses, the high resistivity of the material results in no photovoltaic effect. Although the measurements shown here demonstrate a decrease license or copyright; see http://apl.aip.org/about/rights and permissions reduction in $\mathrm{QE}$ with an applied bias of only $0.28 \mathrm{~V}$, as 


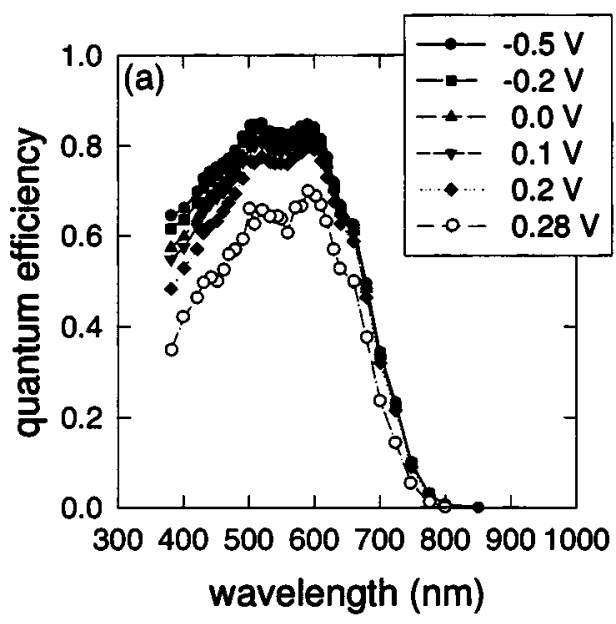

in the external parameters, in particular the value of $V_{\mathrm{oc}}$, an improvement in the spectral response in the 400-500-nm regime has been observed. This has been attributed to the wider band gap of the $p$ layer, resulting in lower optical absorbance in this wavelength range. The external parameters of the PAC-containing film are comparable to standard $a-\mathrm{Si}: \mathrm{H}$ solar cells that only utilize $a$-Si layers as opposed to an $a$-Si:C $p$ layer. Future research should be directed towards lowering the activation energy of the PAC layer, as this will limit the open-circuit voltage, as long as the absorption response of the layer is not compromised.

The authors acknowledge discussions with G. A. J. Amaratunga.

${ }^{1}$ S. R. P. Silva, J. D. Carey, R. U. A. Khan, E. G. Gerstner, and J. V. Anguita, Handbook of Thin Films (Academic, New York, 2000).

${ }^{2}$ N. L. Rupesinghe, R. J. Cole, M. Chhowalla, G. A. J. Amaratunga, and P. Weightman, Diamond Relat. Mater. 9, 1148 (2000).
${ }^{3}$ K. M. Krishna, M. Umeno, Y. Nukaya, T. Soga, and T. Jimbo, Appl. Phys. Lett. 77, 1472 (2000).

${ }^{4}$ R. U. A. Khan, A. P. Burden, S. R. P. Silva, J. M. Shannon, and B. J. Sealy, Carbon 37, 777 (1999).

${ }^{5}$ C. A. Davis, S. R. P. Silva, R. E. Dunin-Borkowski, G. A. J. Amaratunga, K. M. Knowles, and W. M. Stobbs, Phys. Rev. Lett. 75, 4258 (1995).

${ }^{6}$ D. R. McKenzie, D. Muller, and B. A. Pailthorpe, Phys. Rev. Lett. 67, 773 (1991).

${ }^{7}$ D. Dasgupta, F. Demichelis, and A. Tagiaferro, Philos. Mag. B 63, 1255 (1991).

${ }^{8}$ C. W. Chen and J. Robertson, J. Non-Cryst. Solids 227, 602 (1998).

${ }^{9}$ R. U. A. Khan, J. D. Carey, S. R. P. Silva, B. J. Jones, and R. C. Barklie, Phys. Rev. B 63, 121201 (2001).

${ }^{10}$ C. H. Lee and K. S. Lim, Appl. Phys. Lett. 72, 106 (1998).

${ }^{11}$ C. H. Lee and K. S. Lim, Appl. Phys. Lett. 75, 569 (1999).

${ }^{12}$ M. Zeman, R. A. C. M. M. van Swaaij, E. Schroten, L. L. A. Vosteen, and J. W. Metselaar, Mater. Res. Soc. Symp. Proc. 507, 409 (1998).

${ }^{13}$ J. V. Anguita, S. R. P. Silva, A. P. Burden, B. J. Sealy, S. Haq, M. Hebron, I. Sturland, and A. Prichard, J. Appl. Phys. 86, 6276 (1999).

${ }^{14}$ R. U. A. Khan, A. C. Ferrari, and S. R. P. Silva (unpublished).

${ }^{15}$ R. A. Street, Hydrogenated Amorphous Silicon (Cambridge University Press, Cambridge, UK, 1991). 